\title{
Assessment of various parametric effects on the performance of a commercial grade photovoltaic solar panel
}

\author{
Susanta K. Das, ${ }^{*}$ and David Frank \\ Department of Mechanical Engineering, Kettering University, 1700 University Avenue, Flint, MI 48504, USA.
}

\begin{abstract}
This paper presents the implementation of an integrated photovoltaic solar panel model which includes all the necessary parameters in order to simulate and analyze using Matlab/Simulink software. The integrated photovoltaic model is validated with Matlab/Simulink simulation for a commercially available $100 \mathrm{~W}$ photovoltaic solar panel module. Using the commercial solar panel specifications, such as solar irradiation, panel temperature, etc. the integrated model solved with Matlab/Simulink returns an I-V and P$\mathrm{V}$ performance characteristics under various conditions which enabled detailed analysis, assessment of parametric effect on the performance of the solar panel. According to the model simulation results for a commercial RNG-100D solar panel, it was found that panel performance was mostly affected by the variations of solar radiation/insolation, panel surface temperature, series resistance, shunt resistance and band gap energies of the semiconductor materials. The commercial solar panel simulation results show that a photovoltaic panel output power reduces as module temperature decreases. Taking the effect of sunlight irradiance and cell temperature into consideration, the output current and power characteristics of PV model are simulated and results can be optimized using the proposed model. The integrated model enables the dynamics of PV power system to be easily simulated, analyzed, and optimized.
\end{abstract}

\section{Introduction}

Increasing world population and rapid expansion of industrialization have put an excessive strain on the fossil fuel based energy supply chain. Fossil fuels such as gas, coal, oil and derivatives of oil account for over $80 \%$ of the world's primary energy consumption and out of which $58 \%$ is consumed by the transportation sector and rest are used to meet the electrical energy demand [1-3]. Continuous burning of fossil fuels resulted gradual depletion of natural fossil fuel reserve and pollute global climate due to emission of greenhouse gases which compelled policy makers to take action for reduced dependency on fossil fuels and look for renewable energy resources to meet the growing energy demand.

Solar energy is a renewable, environment friendly and inexhaustible source of energy. Moreover, solar energy has numerous direct or indirect advantages such as (i) it does not deplete natural resources, (ii) does not release harmful greenhouse gas emission into air and water or generates liquid or solid waste products, (iii) can accelerate rural or remote areas electrification in developing countries, (iv) may reduce transmission lines from electricity grids, (v) may rescue degraded land, (vi) may increase regional/national energy independence, (vii) may enhance diversification and security of energy and (viii) provide healthy environment by harnessing usable energy. Furthermore, solar ray or radiation is available virtually at any location on the entire earth surface [2-4]. The sun's average radiation intensity to the earth surface is about $1.35 \mathrm{~kW} / \mathrm{m}^{2}$. The solar power density within the diameter of the exposed surface area of the earth is $178 \times 10^{6}$ MW. The amount of solar energy can be harnessed from the entire surface of the earth is $1.22 \times 10^{14}$ tons coal equivalent or $0.814 \times 10^{14}$ tons of oil equivalent in one year. That is to say, the amount of incoming solar energy on the earth surface in one year is fifty times the known reserves of coal and 800 times the known oil reserves [8]. Hence, if solar energy can be harnessed and used in a proper way, it has the capacity to fulfil multiple times the energy demands of the world population. Since the solar being thousands of time larger as energy source than the present energy consumption rate in the world and hence it enables more and more research in the field of solar energy so that the present and future energy needs of the world can be met.

The solar energy is a dilute source of energy and its availability varies significantly with time and earth's surface location. Now the primary question arises as how to harness solar energy? One important way to convert solar radiation into useful electrical energy through the photovoltaic (PV) effect which is the emergence of an electric voltage between two electrodes attached to a solid or liquid system upon shining light onto the system [3-8]. Photovoltaic (PV) solar cell is basically a $p-n$ junction fabricated in a thin wafer or layer of semiconductor. Usually semiconductor materials absorb a large part of the solar spectrum. As PV cell exposed to the sunlight, photons with energy greater than the bandgap energy of the semiconductor are absorbed and create

*Corresponding author: sdas@kettering.edu 
some electron-hole pairs proportional to the incident irradiation. Under the influence of the internal electric fields of the $p-n$ junction, these carriers are swept apart and create a photocurrent which is directly proportional to the incident radiation or solar insolation [4-6]. When the PV cell is short circuited, the current flows in the external circuit; when open circuited, the current is shunted internally by the intrinsic $p-n$ junction diode. The characteristics of this diode therefore set the open circuit voltage characteristics of the PV cell [3-6]. Since a typical PV cell produces less than $2 \mathrm{~W}$ at $0.5 \mathrm{~V}$, the PV cells must be connected in series configuration to form a PV module to produce required amount of power. A PV solar panel is a group of several PV modules those are electrically connected in series and parallel circuits to generate the required current and voltage to meet the power demand. Since a PV solar panel integrate current electronics, it is difficult to simulate and analyze the PV computational model which motivates to develop an integrated PV solar panel model. In this study, an integrated PV solar panel model has been developed and simulated the model using Matlab/Simulink package and conducted detailed assessment of the effects of various physical parameters on the performance of the PV solar panel.

\section{PV solar panel model and governing equations}

The actual photovoltaic solar panel is the result of combination of a group of photovoltaic cells arranged in series and parallel orientations with their protection devices and energy conversion unit as shown in the Figure 1 .

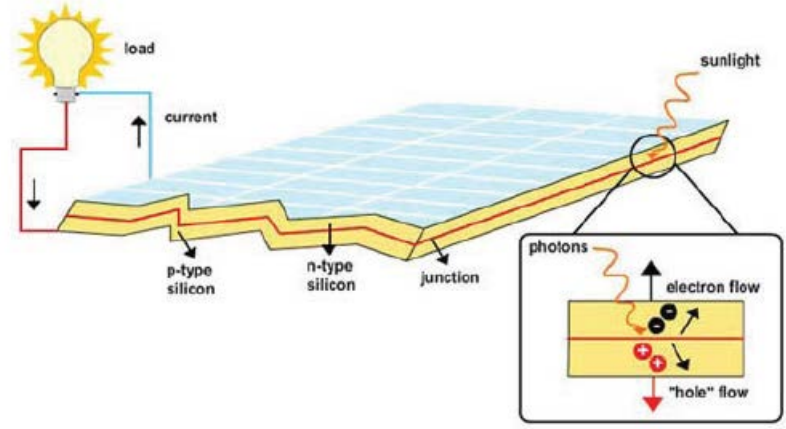

Fig. 1. Schematic of PV cells with p-n junctions in a solar panel and solar energy production mechanism [9].

Hence, the equivalent circuit approach with resistances arranged in parallel and series can be used to develop an integrated computer model for simulation of the actual PV solar panel performance as shown in Fig. 2.

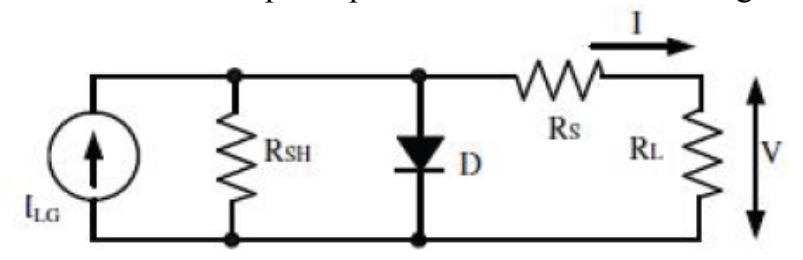

Fig.2. Schematic of equivalent circuit diagram representing PV solar panel [10].
Mathematical model equations of a PV cell has been studied for over past several decades to understand the PV cells I-V output characteristics [1-5] using equivalent circuit approach. As shown in Fig. 2, the equivalent circuit model consists of a photo current, a diode, a parallel resistor expressing a leakage current, and a series resistor describing an internal resistance to the current flow. The voltage-current characteristic equation of the PV solar cell can be written as [3-6]:

$$
\begin{gathered}
I_{P V}=I_{P H}-I_{S}\left[\exp \left(\frac{q\left(V_{P V}+I_{P V} R_{S}\right)}{k T_{c} A}\right)-1\right]-\frac{\left(V_{P V}+I_{P V} R_{S}\right)}{R_{S H}} \\
\text { where } I_{P V} \text { is the cell current, } I_{P H} \text { is the }
\end{gathered}
$$
photocurrent, $I_{S}$ is the cell saturation current, $q\left(=1.6 \times 10^{-19} \mathrm{C}\right) \quad$ is an electron charge, $k\left(=1.38 \times 10^{-23} \mathrm{~J} / k\right)$ is the Boltzmann's constant, $T_{C}$ is the cell's operating temperature, $A$ is the field factor, $R_{S H}$ is the shunt resistance, and $R_{S}$ is the series resistance. The photocurrent mainly depends on the solar radiation and cell's operating temperature, which is described as

$I_{P H}=\left[I_{S C}+k_{I}\left(T_{C}-T_{r e f}\right)\right] \cdot \frac{\beta}{1000}$

where $I_{S C}$ is the cell's short-circuit current at a reference temperature and unit intensity of solar radiation per square meter, $k_{I}$ is the cell's short-circuit current temperature coefficient, $T_{r e f}$ is the cell's reference temperature, and $\beta$ is the solar radiation or insolation in $\mathrm{kW} / \mathrm{m}^{2}$. The cell's saturation current varies with the cell temperature as [2-6]

$I_{S}=I_{R S}\left(T_{C} / T_{r e f}\right)^{3} \exp \left[\left(\frac{1}{T_{r e f}}-\frac{1}{T_{c}}\right) \frac{q E_{g}}{k A}\right]$

where $I_{R S}$ is the cell's reverse saturation current at a reference temperature and a solar radiation, $E_{g}$ is the bang-gap energy of the semiconductor used in the PV cell. The field factor $A$ is dependent on PV technology [3-6]. The PV cell reverse saturation current can be described as [2-6]

$$
I_{R S}=\frac{I_{S C}}{\left[\exp \left(\frac{q V_{o c}}{k A T_{C}}\right)-1\right]}
$$

where $V_{o c}$ is the open-circuit voltage which can be obtained by assuming the output current is zero and $I_{S C}$ is the short-circuit current. 
If the PV solar panel is made by arranging $N_{p}$ number of PV cells in parallel and $N_{s}$ number of PV cells in series then the equivalent circuit equation for representing the solar panel's current and voltage characteristics can be written as [2-7].

$I_{P V}=N_{p} I_{P H}-N_{p} I_{S}\left[\exp \left(\frac{q\left(V_{P V} / N_{s}+I_{P V} R_{S} / N_{p}\right)}{k T_{c} A}\right)-1\right]-\frac{\left(N_{p} V_{P V} / N_{s}+I_{P V} R_{S}\right)}{R_{S H}}$

For an ideal PV solar cell, there is no series loss and no leakage to ground, i.e., $R_{S}=0$ and $R_{S H}=\infty$. Furthermore, normally photo current is much larger than the saturation current $\left(I_{P H} \gg I_{S}\right)$ and ignoring the small diode and ground-leakage currents under zeroterminal voltage, then the short-circuit current $I_{S C}$ is approximately equal to the photocurrent $I_{P H}$, i.e., $I_{P H}=I_{S C}$. The maximum power of the PV cell can be expressed as

$$
\begin{aligned}
& F F=\frac{P_{\max }}{V_{o c} \cdot I_{S C}}=\frac{V_{\max } \cdot I_{\max }}{V_{o c} \cdot I_{S C}} \\
& P_{\max }=V_{\max } \cdot I_{\max }=F F \cdot V_{o c} \cdot I_{S C}
\end{aligned}
$$

where $V_{\max }$ and $I_{\max }$ are the terminal voltage and output current of the PV cell at maximum power point and FF is the cell fill factor which is a measure of the cell quality. The PV cell's efficiency can then be calculated as

$\eta=\frac{P_{\max }}{P_{\text {in }}}=\frac{V_{\max } \cdot I_{\max }}{A_{\text {area }} \cdot G_{\text {in }}}$

where $G_{\text {in }}$ is the solar radiation flux occurs on the PV cell.

\section{Simulation results of PV solar panel and discussions}

In this study, we integrated all the parameters needed to consider in the mathematical model through equations (1)-(8).

Table 1. RNG-100D Specifications $\left(1 \mathrm{~kW} / \mathrm{m} 2,25^{\circ} \mathrm{C}\right)$.

\begin{tabular}{|l|c|}
\hline \multicolumn{1}{|c|}{ Characteristics } & Specification \\
\hline Maximum Power at STC (Pmax) & $100 \mathrm{~W}$ \\
\hline Voltage at Max Power (Vmax) & $18.9 \mathrm{~V}$. \\
\hline Current at Max Power (Imax) & $5.29 \mathrm{~A}$ \\
\hline Open circuit voltage (Voc) & $22.5 \mathrm{~V}$ \\
\hline Short circuit current (Isc) & $5.75 \mathrm{~A}$ \\
\hline Maximum system voltage & $600 \mathrm{VDC}$ \\
\hline Temperature Coefficient of Pmax & $-0.44 \% /{ }^{\circ} \mathrm{C}$ \\
\hline
\end{tabular}

\begin{tabular}{|l|c|}
\hline Temperature Coefficient of Voc & $-0.30 \% /{ }^{\circ} \mathrm{C}$ \\
\hline Temperature Coefficient of Isc (Ki) & $0.04 \% /{ }^{\circ} \mathrm{C}$ \\
\hline $\begin{array}{l}\text { Nominal Operating Cell } \\
\text { Temperature (NOCT) }\end{array}$ & $47 \pm 2{ }^{\circ} \mathrm{C}$ \\
\hline Operating Module Temperature & $-40^{\circ} \mathrm{C}$ to $+80^{\circ} \mathrm{C}$ \\
\hline
\end{tabular}

The integrated mathematical model was simulated using a refined Matlab/Simulink block-diagram program [11]. To simulate and validate the integrated model equations (1)-(8), we used a high performance commercial Renogy RNG-100D [12] 100W monocrystalline PV solar panel. The parametric specifications of the RNG-100D solar panel are shown in Table 1. The specifications given in Table 1 are used to simulate the integrated model using Matlab/Simulink program to study the effect of various model parameters on the characteristics performance of the RNG-100D solar panel.

Figure 3 represents the $I-V$ performance curve of a commercially available solar panel, RGN-100D, for different band gap energies. Band gap energy describes jump in potential between a higher and lower electron state. In essence, it is the 'gap' in which no electron states can exist. Thus, for any given semiconductor material, higher and lower electron states differ only by an integer multiple of a constant. That constant, in $\mathrm{eV}$, is a material's band gap energy. In the context of PV cells, a lower band gap energy correlates to a higher short circuit voltage according to equations (1) and (3). As far as performance is concerned, the results in Figure 3 suggest that lower band gaps are ideal, however the limited effect on performance could easily be considered trivial.

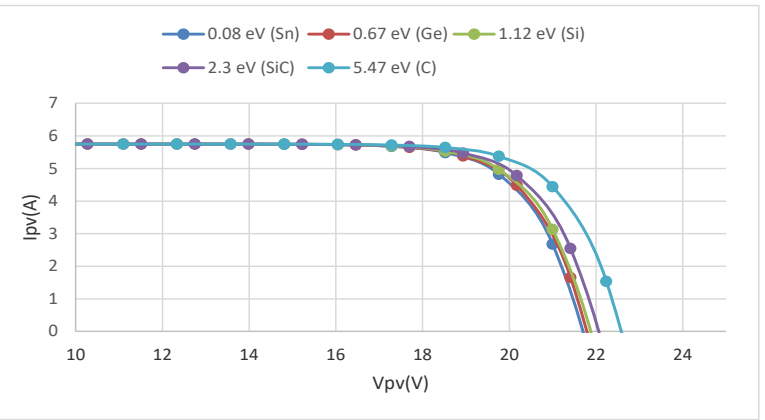

Fig. 3. $I-V$ Curves for diffèrent band gap énergies of RNG100D solar panel

Figure 4 represents the power output of a commercially available RNG-100D solar panel for different band gap energies. The band gaps' effect on power output is directly proportional to its effect on short circuit voltage, and its effects are noticeably small as can be seen from Fig. 4. This comes as no surprise since equation (6) defines power as the product of voltage and current. Yet again, the results from Fig. 4 suggested that lower bandgaps are ideal although the effect on the solar panel performance remains small.

Figure 5 shows performance curves for different amount of solar radiations/flux intensities on a commercially available RNG-100D solar panel. From 
Figure 5 it can be seen that the different solar intensities produce the most significant effects on the $I-V$ characteristics of the solar panel. This should come as no surprise as sunlight is the 'prime mover' as it were, in PV cells and panels alike. Moreover, equations (1) and (2) affirm this. And as those equations imply, the effect is almost perfectly scalar with the effect seen in an individual PV cell.

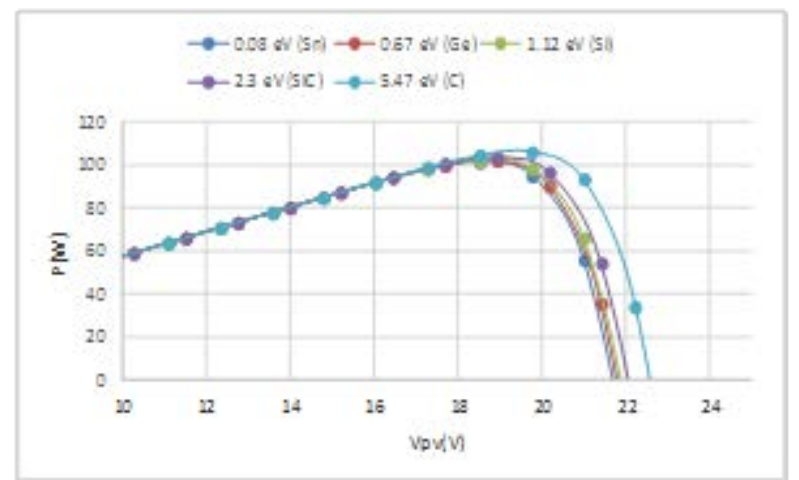

Fig. 4. $P-V$ Curves for different band gap energies of RNG$100 \mathrm{D}$ solar panel.

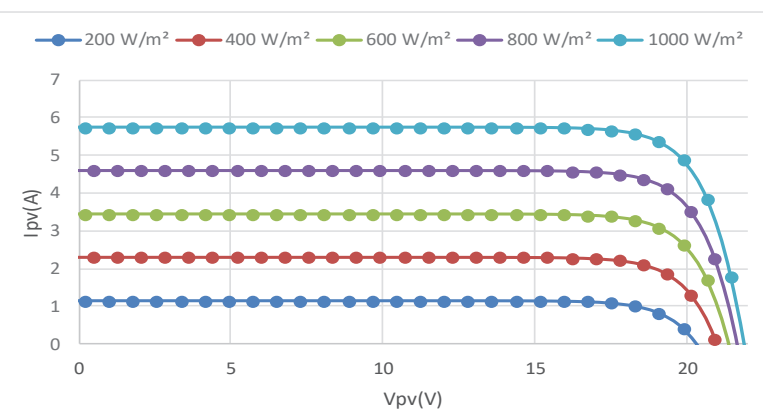

Fig. 5. $I-V$ Curves for different solar radiations on RNG-100D solar panel.

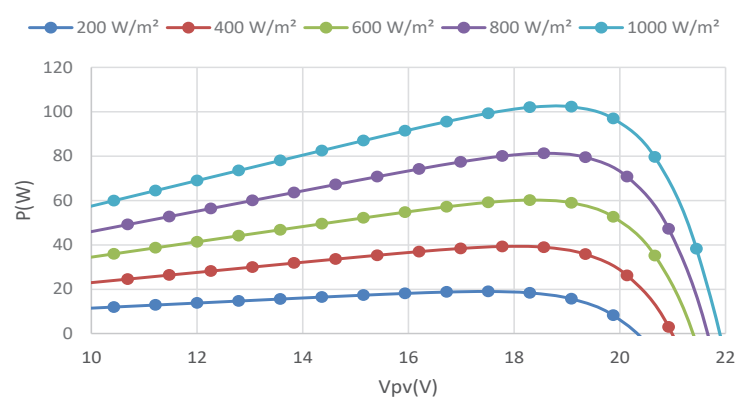

Fig. 6. $P-V$ Curves for different Solar Radiations of RNG100D solar Panel.

Figure 6 represents power curves for different solar radiations for a commercially available RNG-100D solar panel. In accordance with equations (1) and (2), the voltage is unaffected by solar radiation/intensity. Be that as it may, power still suffers as it is a function of current via equation (6). The figure clearly illustrates these predictions.

Figure 7 represents $I-V$ performance curves for different temperatures for the commercially available
RNG-100D solar panel. From Figure 7 it can be seen that initially the solar panel produce about 5.9A constant current as voltage increases up to $16 \mathrm{~V}$. As voltage increases the current production drops sharply with decreased temperature. Figure 8 represents power curves for different temperatures for a commercially available solar panel. Although current is only marginally increased, the subsequent deficit in voltage has a significant effect on power. From Figure 8 it is noted that the wide variation in maximum power for each temperature. Equations (2) and (3) define this effect. This figure reaffirms the conclusion that temperature has a near identical effect on performance regardless of scale. The effect is as significant as it is consistently observed in other solar panel.

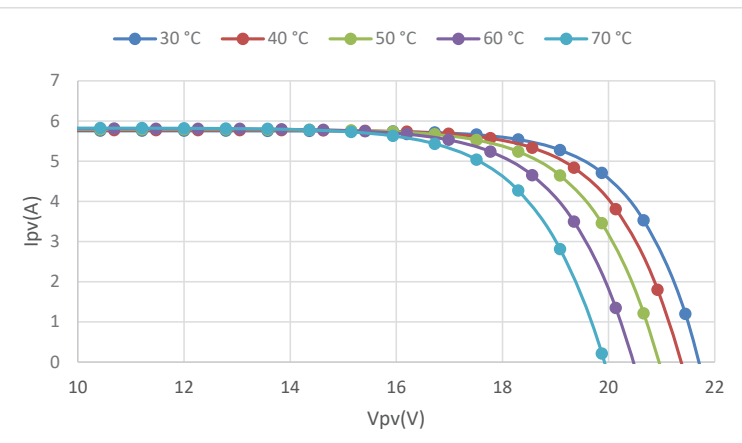

Fig. 7. I- $V$ Curves for different surface temperature of RNG100D solar panel.

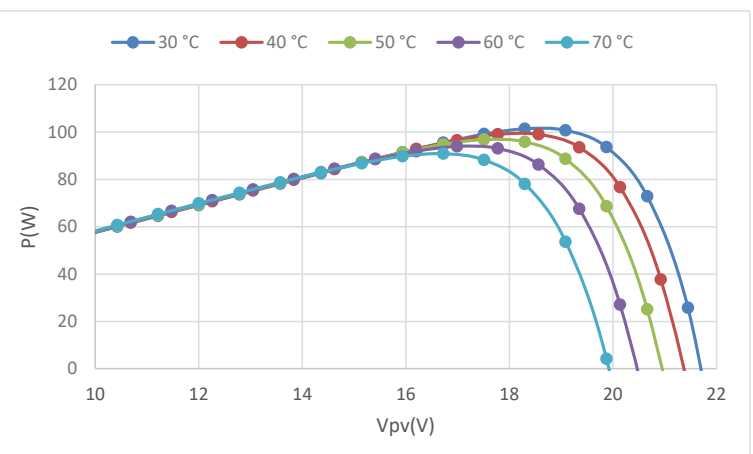

Fig. 8. $P-V$ Curves for different surface temperature of RNG100D solar panel.

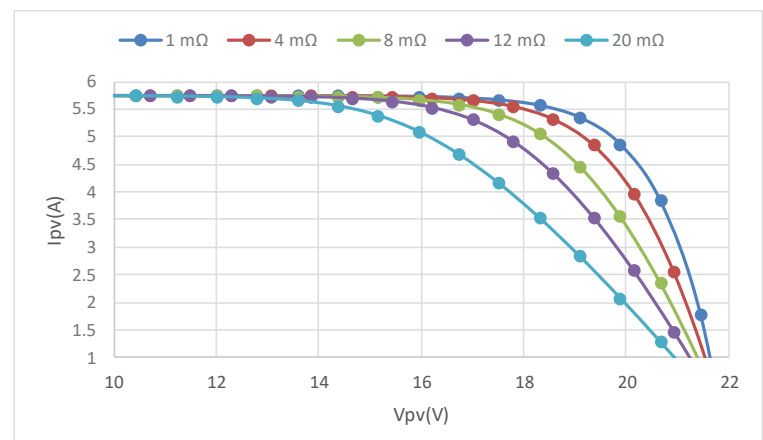

Fig. 9. I- $V$ Curves for different series resistances of RNG-100D solar panel.

Figure 9 represents $I-V$ performance curves for different series resistances for a commercially available 
RNG-100D solar panel. According to Ohm's Law, it was assumed that the total series resistance of the panel would affect its performance in a perfectly linear fashion. The results in Figure 9 do affirm that prediction.

Figure 10 represents $I-V$ performance curves for different shunt resistances for a commercially available RNG-100D solar panel. Shunt resistance is an undesired short circuit between the front and back contacts of a solar cell. It is an unavoidable consequence of PV cell manufacture and usually worsens over a cell's lifetime due to wafer damage. For that reason it can be seen as an indicator of quality in a brand new solar panel as well as an indicator of condition in older ones. The results presented in Figure 10 displays how as the shunt resistance decreased, performance of the solar cell dwindled. This can be explained as having increased the number of short circuits, effectively wasting cell current. A higher resistance better resists the flow of this wasted current.

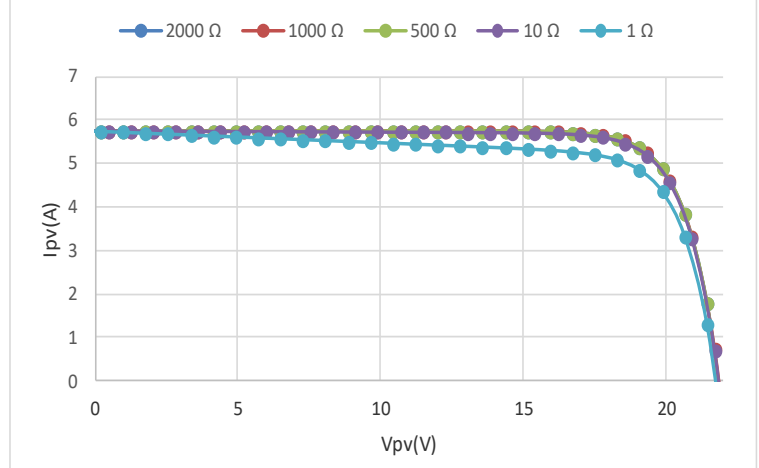

Fig. 10. $I-V$ Curves for different shunt resistances of RNG100D solar panel.

\section{Conclusions}

An accurate photovoltaic solar panel module is presented based on equivalent circuit approach and demonstrated in Matlab/Simulink for a commercially available Renogy RNG-100D 100W photovoltaic solar panel. The outlined integrated PV solar model is easy to implement on proposed refined Matlab/Simulink modeling and simulation platform. Using the refined Matlab/Simulink block diagram there is now an integrated PV model which can be used for the model and analysis in the filed of PV panel solar energy conversion system. Using the commercial solar panel manufacturer specifications, such as solar irradiation, panel temperature, etc. the integrated model solved with Matlab/Simulink returns an $\mathrm{I}-\mathrm{V}$ and $\mathrm{P}-\mathrm{V}$ characteristics under various conditions which enabled detailed analysis, assessment of various parametric effect on the performance of the solar panel. Based on the model simulation results for a commercial RNG-100D solar panel it was found that panel performance was mostly affected by the variations of solar radiation/insolation, panel surface temperature, series resistance, shunt resistance and band gap energies of the semiconductor materials. The commercial solar panel simulation results show that a photovoltaic panel output power reduces as module temperature decreases. The integrated model results obtained by simulation with Matlab/Simulink can be used to optimized solar panel performance and manufacturing process.

\section{References}

1. M. Buresch, McGraw-Hill, NY, (1983).

2. S. W. Angrist, Allyn and Bacon, Inc, $4^{\text {th }}$ edition (1982).

3. A. Kumar, K. Kumar, N. Kaushik, S. Sharma, S. Mishra, Renewable and Sustain. Energy Reviews, 14(8), (2010).

4. J. C. H. Phang, D. S. H. Chan, and J. R. Philips, Electronics Letters, 20(10), (1984).

5. S. Rustemli and F. Dincer, J. Electronics and Electrical Engineering, 35 (2011).

6. S. Nema, R. Nema, and G. Agnihotri, Int.l J. Energy Environ., 1(3) (2010).

7. A. Mellora, D. A. Alvareza, I. Guarracinob, A. Ramosb, A. R. Lacastac, L. F. Llind, A.J. Murrelle, D.J. Pauld, D. Chemisanac, C.N. Markidesb, N.J. Ekins-Daukes, J. Solar Energy, 174 (2018).

8. A. Ramos, M. A. Chatzopoulou, I. Guarracino, J. Freeman, C. N. Markides, J. Energy Conversion and Management 150 (2017).

9. B. Miedzinski, Electronics and Electrical Eng. Kaunas: Technologija. 5(101), (2010).

10. M. Demirta|, e-Journal of New World Sciences Academy, 4(3), (2009).

11. J. B. Dabney and T. L. Harman, Mastering Simulink, Pearson Education,Inc. (2004).

12. Renogy. (n.d.). RNG-100D. Retrieved from www.renogy.com (2019) 